\title{
THE POPULATION GENETIC STRUCTURE OF VECTORS AND OUR UNDERSTANDING OF DISEASE EPIDEMIOLOGY
}

\author{
McCOY K.D.*
}

\section{Summary:}

Understanding and predicting disease epidemiology relies on clear knowledge about the basic biology of the organisms involved. Despite the key role that arthropod vectors play in disease dynamics and detailed mechanistic work on the vectorpathogen interface, little information is often available about how these populations function under natural conditions. Population genetic studies can help fill this void by providing information about the taxonomic status of species, the spatial limits of populations, and the nature of gene flow among populations. Here, I briefly review different types of population genetic structure and some recent examples of where this information has provided key elements for understanding pathogen transmission in tick-borne systems.

KEY WORDS : tick-borne disease, genetic epidemiology, molecular markers, vector control, pathogen evolution.

1 The medical and economic impacts of vector-borne disease are incontestable. However, much basic information on the taxonomy and ecology of these systems is unknown, and particularly that of the vectors responsible for disease transmission. For example, many studies have focused on pathogenic trypanosomes transmitted by tsetse flies, but this knowledge is largely without reference to their vectors (Gooding \& Krafsur, 2005). We can now find molecular evidence for sympatric divergence of malaria pathogens within avian host species. However, the factor driving this divergence is unknown; the vector is likely the key for understanding this diversity, but in most cases has yet to be identified (Pérez-Tris et al., 2007). The former view of arthropod vectors as vehicles for reaching the host with no impact on the pathogen is changing as more and more studies demonstrate that pathogens can significantly alter vector biology and that there is a strong genetic basis for vector competence (reviewed in Gooding, 1996).

The lack of information on vectors may lie in part with the difficulty inherent in studying them because of their

\footnotetext{
* Génétique et Évolution des Maladies Infectieuses, UMR 2724 CNRS-IRD, Centre IRD, 911, avenue Agropolis, BP 64501, F-34394 Montpellier, France.

Tel.: 33 (0)4 67416207 - Fax : 33 (0)4 67416299

Email: mccoy@mpl.ird.fr
}

small size, the inability to follow them directly under natural conditions, and the daunting task of trying to determine which species are involved in transmission cycles when pathogen prevalence is low. Polymorphic molecular markers and the way this polymorphism is distributed within and among pre-defined subsets of individuals (i.e. population genetics) can provide insight into many ecological features of these organisms including reproductive modes and/or strategies, dispersal, and population size and structure (Tabachnick \& Black IV, 1995; see De Meeûs et al., 2007 for a detailed review of population genetic techniques and analyses). They also provide a means of simultaneously studying the microparasites harboured by these vectors with greater ease than in the past (e.g., Mohanty et al., 2007). The wide-spread availability of these tools has opened the way to the development of integrated genetic epidemiology - the study of the population genetics of infectious diseases and their vectors (Tibayrenc, 1998), a discipline that aims to establish the patterns and determinants of the spatial and temporal distribution of disease.

In this short review, I hope to convince the reader of the insight to be gained from studying the population genetics of vectors. I first discuss the types of information these studies can provide and the implications of different population genetic structures for epidemiology. To illustrate these points, I review some recent examples of tick vectors where population genetic studies have provided key elements for understanding pathogen transmission.

\section{WHAT CAN THE POPULATION STRUCTURE OF VECTORS TELL US?}

Tf we wish to predict the dynamics of disease epidemics, we must first understand key factors linked to transmission through the vector such as the biological diversity involved, the population dynamics of these species, and the spatial extent of their population. Population genetic studies can provide incite on many of these aspects. For example: 
- Cryptic vector species

Epidemiological studies assume that we understand the taxonomic status of the organisms involved in the disease cycle. However, how much of what we interpret as intraspecfic variation is actually interspecific? Numerous genetic studies have revealed the presence of cryptic vector species (e.g., Beebe \& Cooper, 2000; Vial et al., 2006b). The presence of these species can change our perception of the pathogen-vector-host interaction (Fig. 1). Different vector species may show different degrees of competence (i.e., the innate ability to acquire pathogens and pass them to a susceptible host) and thus population parameters associated with vector population dynamics, along with selection on the pathogen, will be strongly affected.

- Population structure and transmission

At a lower taxonomic level, the subdivision of the vector into discrete populations (population structure) will also affect the scale at which transmission occurs. Indeed, different population structures can alter disease transmis- sion parameters and modify predictions of disease dynamics (Wonham et al., 2006). As is the case for cryptic vector species, this isolation can lead to inter-populational differences in competence, virulence, resistance, etc.

- Gene flow and colonisation potential

Population genetic data can provide us with estimates of the distance, direction and rate of gene flow between discrete populations. If gene flow is high, the vector may have a high probability of colonizing new areas or recolonizing sites where local control programmes were successful at eradication. Patterns of gene flow across populations can also provide indications of dispersal mechanisms. For example, if population divergence gradually increases with geographic distance (i.e., isolation by distance), natural dispersal of the vectors between neighbouring populations may be occurring. Depending on the biology of the organism, alternative patterns may suggest that other dispersal mechanisms are operating, including anthropogenic sources (e.g., vector migration via human transportation systems). a) One host population - one vector population

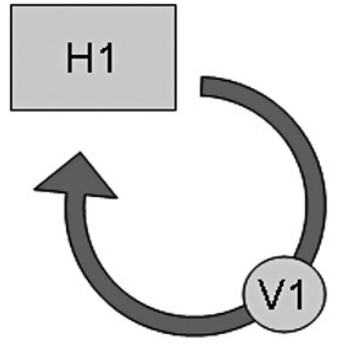

c) Several host populations - one vector population

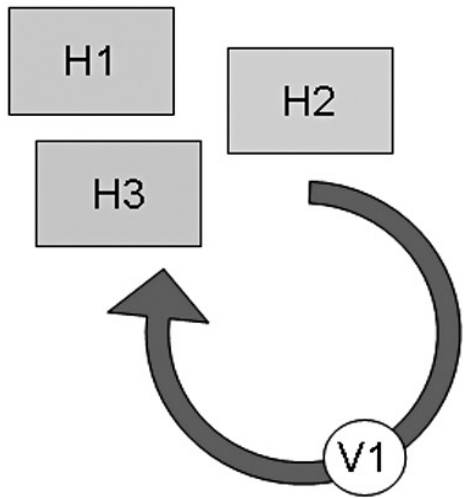

b) One host population - two vector populations

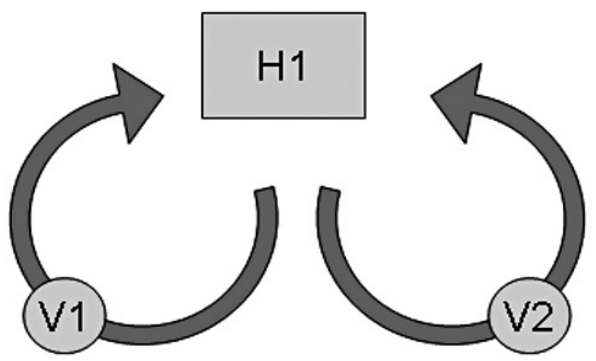

d) Several host populations - several vector populations

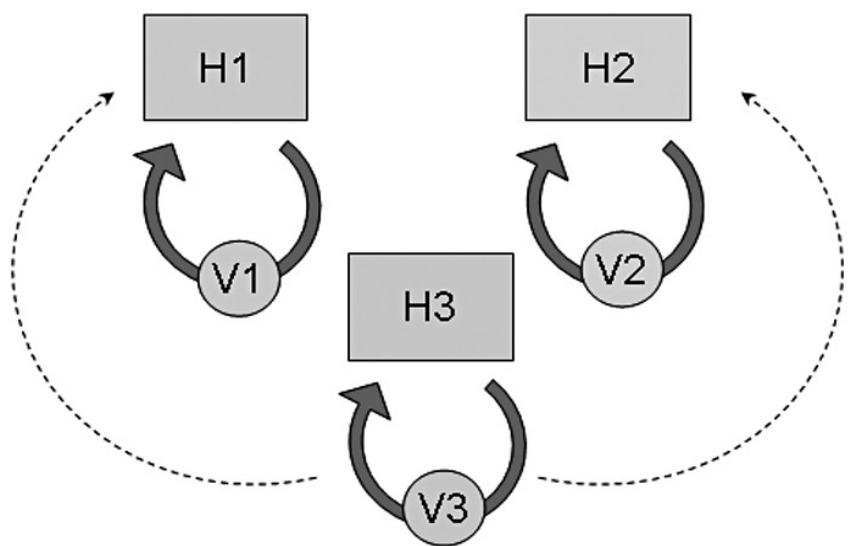

Fig. 1. - Different types of local interactions depending on the population structure of the vector. a) The simplest scenario where a microparasite circulates between one host population and a single vector population. In this case, the microparasite may adapt to efficiently exploit the vector and vertebrate host. b) The vector shows population structure, but both populations exploit the same host population. Here, the microparasite can circulate in both vector populations, but selection in the vector will occur independently (could result in one vector becoming more competent than the other or in the evolution of two microparasite populations via divergent selection). c) Several host species are available locally, but all are equally used by the vector (the vector is a generalist). In this case, the evolution of the microparasite will depend on relative selection pressures imposed by the different hosts. d) Each vertebrate host species is exploited by one vector population resulting in locally independent or semi-independent disease cycles. The outcome of these interactions will depend on the specificity of the different vector populations (dotted line) and the ability of the microparasite to exploit different hosts after transmission. 
- Diversity and local adaptation

Vertebrate-vector-pathogen systems are dynamic and their evolutionary rates will depend upon available genetic variation and the selective pressures applied to each interacting species. Gene flow that increases local genetic variation can be essential in determining host-parasite co-evolutionary outcomes (Gandon \& Michalakis, 2002). It is widely acknowledged that genetic variation in vector populations probably affects the transmission of many parasitic diseases at macrogeographic scales (Gooding, 1996) and, in line with this, numerous studies have found interpopulational variability in susceptibility/resistance to pathogens (e.g., Turell et al., 1992).

\section{IMPLICATIONS OF DIFFERENT POPULATION STRUCTURES}

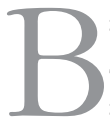
ased on morphological descriptions, vector-borne systems can often seem relatively simple where a microparasite is transmitted between one vector population and one host population in a given location. This type of system is very convenient for models of pathogen dynamics and evolution. However, population genetic studies of vector organisms can often reveal more complex situations. In Figure 1, I outline several possible vector population structures. This structure will intimately affect the ecology and evolution of the system, including pathogen evolution. Knowledge of the genetic structure of a vector is also a fundamental basis for designing vector control programs. If there is limited migration between vector populations, control programs aimed at focal areas of disease infection may be effective. If, however, vector dispersal is wide-spread, large scale programs will be required (Tabachnick \& Black IV, 1995). Such studies can also be used to evaluate the effectiveness of previous control programs by determining the origin of newly established vector populations (e.g., De Rosas et al., 2007).

\section{EXAMPLES}

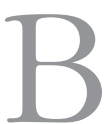

elow I review examples from studies of the population genetic structure of ticks that outline how information about the population structure of these vectors has changed our perception of pathogen transmission. Although I limit these examples to ticks, similar examples also exist for other important vector groups: mosquitoes (e.g., Ravel et al., 2002), sand flies (e.g., Rocha et al., 2007), tsetse flies (e.g., Ravel et al., 2007), and kissing bugs (e.g., De Rosas et al., 2007), etc.

\section{IXODES SCAPULARIS/DAMMINI}

In the eastern United States, Borrelia burgdorferi sensu stricto, a member of the spirochete complex B. burgdorferi sensu lato responsible for Lyme disease, is vectored by the black-legged tick Ixodes scapularis (Ixodidae) (Piesman, 2002). Transmission patterns of B. burgdorferi s.s. are extremely different in the north and south, with high disease incidence in the north and low incidence in the south. These patterns were initially considered due to the presence of different tick vectors with different vectorial capacities in each region, respectively I. dammini and I. scapularis (Fig. 1d). However, morphology and studies of reproductive isolation called their species status into question (Oliver et al., 1993). Analyses of population genetic variation have helped shed light on this question. First, variation at two nuclear genes, ITS1 and ITS2, found that differentiation between populations within each species was of the same magnitude as that between populations of the different species (Wesson et al., 1993). Analyses of the $16 \mathrm{~S}$ and $12 \mathrm{~S}$ mitochondrial genes showed that although all I. scapularis and I. dammini populations formed a monophyletic group with respect to outgroup ticks, two clades could be identified, one corresponding to southern populations, and a second that the authors referred to as the American clade (Norris et al., 1996). Tick populations with a mix of both haplotype groups could be found and further analyses using RAPD markers (randomly amplified polymorphic DNA) revealed no structure across the eastern US.

Based on this data, current gene flow between the species was inferred and justification for the separation of these ticks into two species was lost. Differences in regional patterns of disease transmission are now considered to be best explained by the local availability of different hosts species that show variable degrees of competence for B. burgdorferi s.s. (LoGiudice et al., 2003, but see Telford, 1998). The high availability of lizard hosts (poor competence) in the south and whitefooted mice (high competence) in the north may explain current prevalence estimates (Piesman, 2002). In this case, we have scenario c (Fig. 1), but with the relative availability of the different hosts changing across the distribution.

\section{ORNITHODOROS SONRAI}

In West Africa, tick-borne relapsing fever (TBRF) is caused by the spirochete Borrelia crocidurae and is transmitted by the soft tick Ornithodoros sonrai. Disease incidence is high and increased substantially between 1995 and 2002 in rural areas of Senegal, Mauritania and Mali. The average infection rates of the tick vector across villages can be high $31 \%$ and transmission to humans seems to be linked to the presence of small mammal burrows that open into human habitations 
(Vial et al., 2006a). Species identification of soft ticks in Africa has traditionally been based on morphology, geographic distribution, vector competence and Borrelia specificity. However, the existence of multiple strains of $B$. crocidurae with distinct pathogenic effects that were transmitted only by their local ticks, combined with a decreased fecundity in ticks crossed from different regions, suggested that the situation may be more complex. Samples of ticks from across Senegal and Mauritania were analysed at the 16S rDNA gene. All samples formed a monophyletic group, but the sequence divergence of haplotypes ranged from $0.2 \%$ and $16.8 \%$, greater than between some species of soft ticks (Black IV \& Piesman, 1994). Indeed, four genetically distinct subgroups of $O$. sonrai could be identified. Three of these followed geographical clusters whereas the fourth, the most divergent subgroup, was found on sympatric ranges with the other three. All subgroups were infected by identical $B$. crocidurae (determined by amplification of the flagellin gene), but differences in detected prevalence suggested the possibility of variable competences (Vial et al., 2006b). Here, it is unclear for now which type of transmission scenario we have: one host with at least two vector populations (Figure 1b), or distinct vector-host associations (Fig. 1d). More genetic and ecological work will be required to test for host specificity of these tick subgroups, to examine whether selected variation exists in the pathogen, and to determine how this variation relates to the different vector subgroups.

\section{IXODES URIAE}

Ixodes uriae exploits different colonial seabird species in the circumpolar areas of both hemispheres and supports an enzootic cycle involving the Lyme disease bacterial complex Borrelia burgdorferi sensu lato (Olsen et al., 1993). At least one pathogenic species of this complex has been found in this tick, B. garinii, and seabirds have been suggested to be involved in the longdistance spread of this pathogen (Olsen et al., 1995). Early descriptions of $I$. uriae considered it as a generalist ectoparasite infesting all locally available seabirds (Fig. 1c). However, recent studies using microsatellite genetic markers have shown that this is not the case. Distinct host races have been detected on all seabirds tested to date (McCoy et al., 2001) and these races seem to evolve recurrently in different isolated regions (McCoy et al., 2005). If tick races are completely faithful to their hosts, this could result in several independent, but sympatric, transmission cycles (Fig. 1d). As detailed analyses within each tick race have revealed that the spatial scale of gene flow is host-dependent (McCoy et al., 2003), this isolation will have important consequences for pathogen transmission and coevolutionary interactions. More detailed cha- racterisation of the Borrelia spp. infecting different tick races should provide some insight into how isolated these interactions are in reality and whether there is a direct link between marine and terrestrial enzootic cycles. For the present, it is unclear how frequently host-associated divergence occurs in tick (or other vector) systems. Future studies will need to adapt sampling procedures in order to test more explicitly for this type of population structure.

\section{CONCLUSIONS AND PERSPECTIVES}

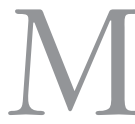
ore than a decade after the call for population genetic studies of vectors (Tabachnick \& Black IV, 1995), we start to see information accumulating and the emergence of a new perspective on the intricacies of vector-borne disease. However, we still have to go the next step. The need for integrated approachs to studying infectious agents is widely recognised (Levin et al., 1999). These approachs must now incorporate what we are learning about vector ecology and genetics to improve our ability to understand and predict the spatial and temporal distribution of vector-borne disease.

\section{REFERENCES}

BEeBE N.W. \& COOPER R.D. Systematics of malaria vectors with particular reference to the Anopheles punctulatus group (vol 30, pg 1, 2000). International Journal for Parasitology, 2000, 30, 1-17.

Black IV W.C. \& Piesman J. Phylogeny of hard- and soft-tick taxa (Acari: Ixodida) based on mitochondrial 16S rDNA sequences. Proceedings of the National Academy of Sciences of USA, 1994, 91, 10034-10038.

De Meeûs T., McCoy K.D., Prugnolle F., Chevillon C., Durand P., Hurtrez-Boussès S. \& Renaud F. Population genetics and molecular epidemiology or how to "débusquer la bête". Infection Genetics and Evolution, 2007, 7, 308-332.

De Rosas A.R.P., Segura E.L. \& Garcia B.A. Microsatellite analysis of genetic structure in natural Triatoma infestans (Hemiptera: Reduviidae) populations from Argentina: its implication in assessing the effectiveness of Chagas' disease vector control programmes. Molecular Ecology, 2007, 16, 1401-1412.

GANDON S. \& MichalaKis Y. Local adaptation, evolutionary potential and host-parasite coevolution: interactions between migration, mutation, population size and generation time. Journal of Evolutionary Biology, 2002, 15, 451-462.

GoODING R.H. Genetic variation in arthropod vectors of diseasecausing organisms: Obstacles and opportunities. Clinical Microbiology Reviews, 1996, 9, 301.

Gooding R.H. \& Krafsur E.S. TSETSE genetics: Contributions to biology, systematics, and control of tsetse flies. Annual Review of Entomology, 2005, 50, 101-123. 
Levin B.R., Lipsitch M. \& Bonhoeffer S. Evolution and disease - Population biology, evolution, and infectious disease: convergence and synthesis. Science, 1999, 283, 806-809.

LoGiudice K., Ostfeld R.S., Schmidt K.A. \& Keesing F. The ecology of infectious disease: effects of host diversity and community composition on Lyme disease risk. Proceedings of the National Academy of Sciences, USA, 2003, 100, 567571.

McCoy K.D., Boulinier T., Tirard C. \& Michalakis Y. Host specificity of a generalist parasite: genetic evidence of sympatric host races in the seabird tick Ixodes uriae. Journal of Evolutionary Biology, 2001, 14, 395-405.

McCoy K.D., Boulinier T., Tirard C. \& Michalakis Y. Hostdependent genetic structure of parasite populations: differential dispersal of seabird tick host races. Evolution, 2003, 57, 288-296.

McCoy K.D., Chapuis E., Tirard C., Boulinier T., Michalakis Y., Le Bohec C., Le Maho Y. \& Gauthier-Clerc M. Recurrent evolution of host-specialized races in a globally distributed parasite. Proceedings of The Royal Society B-Biological Sciences, 2005, 272, 2389-2395.

Mohanty A., Kar P., Mishra K., Singh D.V., Mohapatra N., Kar S.K., Dash A.P. \& Hazra R.K. Multiplex PCR assay for the detection of Anopheles fluviatilis species complex, human host preference, and Plasmodium falciparum sporozoite presence, using a unique mosquito processing method. American Journal of Tropical Medicine and Hygiene, 2007, 76, 837-843.

Norris D.E., Klompen J.S.H., KeIRans J.E. \& Black W.C.I. Population genetics of Ixodes scapularis (Acari: Ixodidae) based on mitochondrial $16 \mathrm{~s}$ and $12 \mathrm{~s}$ genes. Journal of Medical Entomology, 1996, 33, 78-89.

Oliver J.H., Owsley M.R., Hutcheson H.J., James A.M., Chen C.S., Irby W.S., Dotson E.M. \& McLain D.K. Conspecificity of the ticks Ixodes scapularis and Ixodes dammini (Acari: Ixodidae). Journal of Medical Entomology, 1993, 30, 54-63.

Olsen B., Duffy D.C., Jaenson T.G.T., Gylfe A., Bonnedahl J. \& Bergström S. Transhemispheric exchange of Lyme disease spirochetes by seabirds. Journal of Clinical Microbiology, 1995, 33, 3270-3274.

Olsen B., Jaenson T.G.T., Noppa L., Bunikis J. \& Bergström S.A Lyme borreliosis cycle in seabirds and Ixodes uriae ticks. Nature, 1993, 362, 340-342.

Pérez-Tris J., Hellgren O., Kiszanauskiene A., Waldenstrom J., Secondi J., Bonneaud C., Fjeldsa J., Hasselquist D. \& Bensch S. Within-host speciation of malaria parasites. PLOS one, 2007, 2, e235.

PIESMAN J. Ecology of Borrelia burgdorferi sensu lato in North America, in: Lyme Borreliosis: Biology, Epidemiology and Control. Gray J.S., Kahl, O., Lane, R.S. \& Stanek G.(eds), CABI Publishing, New York, 2002, 223-249.

Ravel S., De Meeus T., Dujardin J.P., Zeze D.G., Gooding R.H., Dusfour I., Sane B., Cuny G. \& Solano P. The tsetse fly Glossina palpalis palpalis is composed of several genetically differentiated small populations in the sleeping sickness focus of Bonon, Côte d'Ivoire. Infection Genetics and Evolution, 2007, 7, 116-125.
Ravel S., Herve J.P., Diarrassouba S., Kone A. \& Cuny G. Microsatellite markers for population genetic studies in Aedes aegypti (Diptera: Culicidae) from Côte d'Ivoire: evidence for a microgeographic genetic differentiation of mosquitoes from Bouake. Acta Tropica, 2002, 82, 39-49.

Rocha L.D., Falqueto A., Dos Santos C.B., Grimaldi G. \& CupoLILLO E. Genetic structure of Lutzomyia (Nyssomyia) intermedia populations from two ecologic regions in Brazil where transmission of Leishmania (Viannia) braziliensis reflects distinct eco-epidemiologic features. American Journal of Tropical Medicine and Hygiene, 2007, 76, 559-565.

TABACHNICK W.J. \& BLACK IV W.C. Making a case for molecular population genetic-studies of arthropod vectors. Parasitology Today, 1995, 11, 27-30.

TELFORD S.R. Is the name Ixodes dammini epidemiologically justified. Emerging Infectious Diseases, 1998, 4, 132-134.

Tibayrenc M. Genetic epidemiology of parasitic protozoa and other infectious agents: the need for an integrated approach. International Journal for Parasitology, 1998, 28, 85-104.

Turell M.J., Beaman J.R. \& Tammariello R.F. Susceptibility of selected strains of Aedes aegypti and Aedes albopictus (Diptera: Culicidae) to Chikungunya virus. Journal of Medical Entomology, 1992, 29, 49-53.

Vial L., Diatta G., Tall A., Ba E.H., Bouganali H., Durand P., Sokhna C., Rogier C., Renaud F. \& Trape J.F. Incidence of tick-borne relapsing fever in West Africa: longitudinal study. Lancet, 2006a, 368, 37-43.

Vial L., Durand P., Arnathau C., Halos L., Diatta G., Trape J.F. \& Renaud F. Molecular divergences of the Ornithodoros sonrai soft tick species, a vector of human relapsing fever in West Africa. Microbes and Infection, 2006b, 8, 26052611.

Wesson D.M., Mclain D.K., Oliver J.H., Piesman J. \& Collins F.H. Investigation of the validity of species status of Ixodes dammini (Acari: Ixodidae) using rDNA. Proceedings of the National Academy of Science of the USA, 1993, 90, 1022110225.

Wonham M.J., Lewis M.A., Renclawowicz J. \& VAN DEN DRIESSCHE P. Transmission assumptions generate conflicting predictions in host-vector disease models: a case study in West Nile virus. Ecology Letters, 2006, 9, 706-725. 